\title{
Synthesis of $\mathrm{ZnO} /$ polystyrene composites particles by Pickering emulsion polymerization
}

\author{
Jui Hung Chen ${ }^{a}$, Chu-Yun Cheng ${ }^{a}$, Wen-Yen Chiu ${ }^{a, b, *}$, Chia-Fen Lee ${ }^{c}$, Nai-Yun Liang ${ }^{d}$ \\ anstitute of Polymer Science and Engineering, National Taiwan University Taipei 106, Taiwan \\ ${ }^{\mathrm{b}}$ Department of Chemical Engineering, National Taiwan University Taipei 106, Taiwan \\ ${ }^{\mathrm{c}}$ Department of Cosmetic Science, Chia Nan University of Pharmacy and Science, Tinan 717, Taiwan \\ ${ }^{\mathrm{d}}$ Taiwan Textile Research Institute, Taipei 236, Taiwan
}

\section{A R T I C L E I N F O}

\section{Article history:}

Received 3 September 2007

Received in revised form 26 February 2008

Accepted 18 July 2008

Available online 24 July 2008

\section{Keywords:}

$\mathrm{ZnO}$

Polystyrene

Composite particles

Pickering emulsion polymerization

\begin{abstract}
A B S T R A C T
$\mathrm{ZnO} /$ polystyrene composite particles were synthesized by Pickering emulsion polymerization. $\mathrm{ZnO}$ nanoparticles were first prepared by reaction of zinc acetate and sodium hydroxide in ethanol medium. Then different amount of styrene monomer was emulsified in water in the presence of $\mathrm{ZnO}$ nanoparticles either by mechanical stirring or by sonication, followed by polymerization of styrene. Two kinds of initiators were used to start the polymerization, azobisisobutyronitrile (AIBN) and potassium persulfate (KPS). The X-ray diffraction pattern verified the crystal structure of ZnO and FT-IR spectra evidenced the existence of $\mathrm{ZnO}$ and polystyrene (PS) in $\mathrm{ZnO} /$ polystyrene composite particles. Different morphologies were observed for the composite particles when using different initiators. From TEM photographs, AIBN-initiated system produced mainly core-shell composite particles with PS as core and ZnO as shell, while KPS-initiated system showed both composite particles and pure PS particles. Two schemes of reaction mechanism were proposed to explain the morphologies accordingly. Both systems of composite particles showed good $\mathrm{pH}$ adjusting ability.
\end{abstract}

(c) 2008 Elsevier Ltd. All rights reserved.

\section{Introduction}

In recent years, many efforts have been focused on the inorganic/organic composite materials with various compositions. By combining organic and inorganic materials, the resulting composites can possess advantages of both organic and inorganic components, thus creating extensive usages in many areas. Among the many inorganic materials, zinc oxide, $\mathrm{ZnO}$, is a direct band-gap $(\mathrm{Eg}=3.37 \mathrm{eV})$ semiconductor with a large exciton binding energy $(60 \mathrm{meV})$ [1]. Therefore $\mathrm{ZnO}$ is useful in many application areas such as solar cell [2], gas sensor [3,4], varistors [5], acoustic, and luminescent devices [6-8]. Generally, ZnO can be synthesized by sol-gel method $[9,10]$, homoge-

\footnotetext{
* Corresponding author. Address: Department of Chemical Engineering, National Taiwan University Taipei 106, Taiwan. Tel.: +886 223623259.

E-mail address: ycchiu@ccms.ntu.edu.tw (W.-Y. Chiu).
}

neous precipitation [11], chemical vapor deposition [12], thermal decomposition [13,14], hydrothermal synthesis [15], and reaction of zinc salt with base [16]. Different synthesis routes result in different $\mathrm{ZnO}$ morphology, including particle, rod, tube, and flower-like. Moreover, $\mathrm{ZnO}$ is also an amphoteric substance and has the ability to sense [17] and adjust $\mathrm{pH}$ value, making it useful in biomaterial and textile.

Traditional oil-in-water emulsion polymerization was preceded by adding surfactant to stabilize hydrophobic monomer in aqueous medium. The conventional choice of surfactants includes anionic type, cationic type, zwitterionic type, and nonionic type. Most of them are usually organic compounds containing hydrophilic and hydrophobic group on the molecule or polymer with long chain structure. If the organic surfactants are replaced by inorganic nano-sized particles it is referred as Pickering emulsion polymerization, which was proposed by Pickering in 
1907 [18]. Theoretical and experimental researches of Pickering emulsion polymerization were developed by $\mathrm{He}$ [19-21] and Blinks [22,23]. When the size of inorganic particle is reduced to nanoscale, they are able to assemble on the surfaces of monomer droplets form a stable dispersion. After polymerization inorganic/polymer composite particles can be obtained. Many kinds of inorganic nanoparticles have been reported to be utilized in Pickering emulsion polymerization, including magnetite, cobalt ferrite [24,25], cerium dioxide [26], titania [27], and silica $[28,29]$. The Pickering emulsion polymerization provides a simple and effective way to prepare inorganic/organic composite materials. In this paper, $\mathrm{ZnO} /$ polystyrene composite particles were prepared by Pickering emulsion polymerization. $\mathrm{ZnO}$ nanoparticles were first synthesized from reaction of zinc acetate and sodium hydroxide in ethanol. Then polymerization of styrene with different initiators was conducted in the presence of $\mathrm{ZnO}$ nanoparticles as stabilizer. The morphology of resulting composite particles varied with the selection of initiator of polymerization. The crystal structure was studied with X-ray diffraction and the functional groups of both inorganic and organic components were characterized with Fourier transform infrared spectroscopy. The morphology of $\mathrm{ZnO} /$ polystyrene composite particles was studied with transmission electron microscopy. Finally the $\mathrm{pH}$ adjusting ability of $\mathrm{ZnO} /$ polystyrene composite particles was investigated.

\section{Experiments}

\subsection{Materials}

Zinc acetate and sodium hydroxide $(\mathrm{NaOH})$ purchased from Acros were used as precursor and base in the synthesis of $\mathrm{ZnO}$ nanoparticles. Styrene monomer (St) was also



Fig. 1. TEM of $\mathrm{ZnO}$ nanoparticles. purchased from Acros and used as received. Azobisisobutyronitrile (AIBN) and potassium persulfate (KPS) were used as initiators of polymerization of styrene. Ethanol and DIwater were used as solvents of synthesis of $\mathrm{ZnO}$ nanoparticles and Pickering emulsion polymerization, respectively.

\subsection{Preparation of $\mathrm{ZnO}$ nanoparticles}

$\mathrm{ZnO}$ nanoparticles can be prepared by the reaction of zinc acetate and a base in the alcohol medium. In this study, $1.314 \mathrm{~g}$ zinc acetate and $0.48 \mathrm{~g} \mathrm{NaOH}$ were dissolved in $330 \mathrm{ml}$ ethanol and refluxed at $60^{\circ} \mathrm{C}$ for $1 \mathrm{~h}$. The acetate group reacted with base, converting zinc acetate into zinc oxide. The $\mathrm{ZnO}$ dispersion synthesized in alcohol medium was clear and transparent and was able to maintain stable for at least 2 weeks. After reaction, the zinc oxide ethanol dispersion was mixed with DI-water for purification. $\mathrm{ZnO}$ particles were then separated from the dispersion supernatant by centrifugation at $7000 \mathrm{rpm}$ for $5 \mathrm{~min}$ repeatedly. Finally the $\mathrm{ZnO}$ particles were redispersed in DI-water to obtain $\mathrm{ZnO}$ water dispersion. TEM result indicated that the size of $\mathrm{ZnO}$ particles were about $10-30 \mathrm{~nm}$, as shown in Fig. 1.

\subsection{Pickering emulsion polymerization of $\mathrm{ZnO} /$ polystyrene composite particles}

For AIBN system, styrene monomer and AIBN were first mixed with $10 \mathrm{ml}$ DI-water and then added to $50 \mathrm{ml}$ of $\mathrm{ZnO}$ water dispersion prepared as described in Section 2.2. The mixture was then emulsified either by mechanical stirring $(300 \mathrm{rpm})$ or sonication with a Dr. Hielscher UP50H at $100 \%$ amplitude at $0{ }^{\circ} \mathrm{C}$ for $10 \mathrm{~min}$. After emulsification, the minieulsion was heated to $75^{\circ} \mathrm{C}$ to start the polymerization of styrene under stirring ( $300 \mathrm{rpm}$ ) and a nitrogen atmosphere. After $6 \mathrm{~h}$ of polymerization, the $\mathrm{ZnO} /$ polystyrene composite latex was diluted with methanol and separated from the dispersion supernatant by centrifugation at $13000 \mathrm{rpm}$ for $15 \mathrm{~min}$ repeatedly. As for KPS system, KPS was added after the emulsification of $\mathrm{ZnO}$ and styrene being heated to $75^{\circ} \mathrm{C}$. The $\mathrm{ZnO} /$ polystyrene composite particles were dried to powder in an oven for further characterization. The compositions of recipes to prepare different $\mathrm{ZnO} /$ polystyrene composite particles were listed in Table 1.

Table 1

Composition of recipes to prepare $\mathrm{ZnO} /$ polystyrene composite particles

\begin{tabular}{lllll}
\hline Sample & $\begin{array}{l}\text { Styrene } \\
\text { monomer }(\mathrm{g})\end{array}$ & $\begin{array}{l}\text { ZnO dispersion } \\
(\mathrm{ml})\end{array}$ & $\begin{array}{l}\text { Emulsification } \\
\text { Initiator }\end{array}$ \\
\hline PS1ZnO(A) & 0.1 & 50 & $\begin{array}{l}\text { Mechanical } \\
\text { stirring }\end{array}$ & AIBN \\
PS2ZnO(A) & 0.2 & & Sonification & AIBN \\
PS3ZnO(A) & 0.3 & 50 & & \\
PS1ZnOs(A) & 0.1 & & Mechanical & KPS \\
PS2ZnOs(A) & 0.2 & & stirring & \\
PS3ZnOs(A) & 0.3 & 50 & Sonification & KPS \\
PS1ZnO(K) & 0.1 & & & \\
PS2ZnO(K) & 0.2 & & & \\
PS3ZnO(K) & 0.3 & 50 & & \\
PS1ZnOs(K) & 0.1 & & & \\
PS2ZnOs(K) & 0.2 & & & \\
PS3ZnOs(K) & 0.3 & & &
\end{tabular}

a Weight of initiator is $1 \%$ of weight of styrene monomer. 


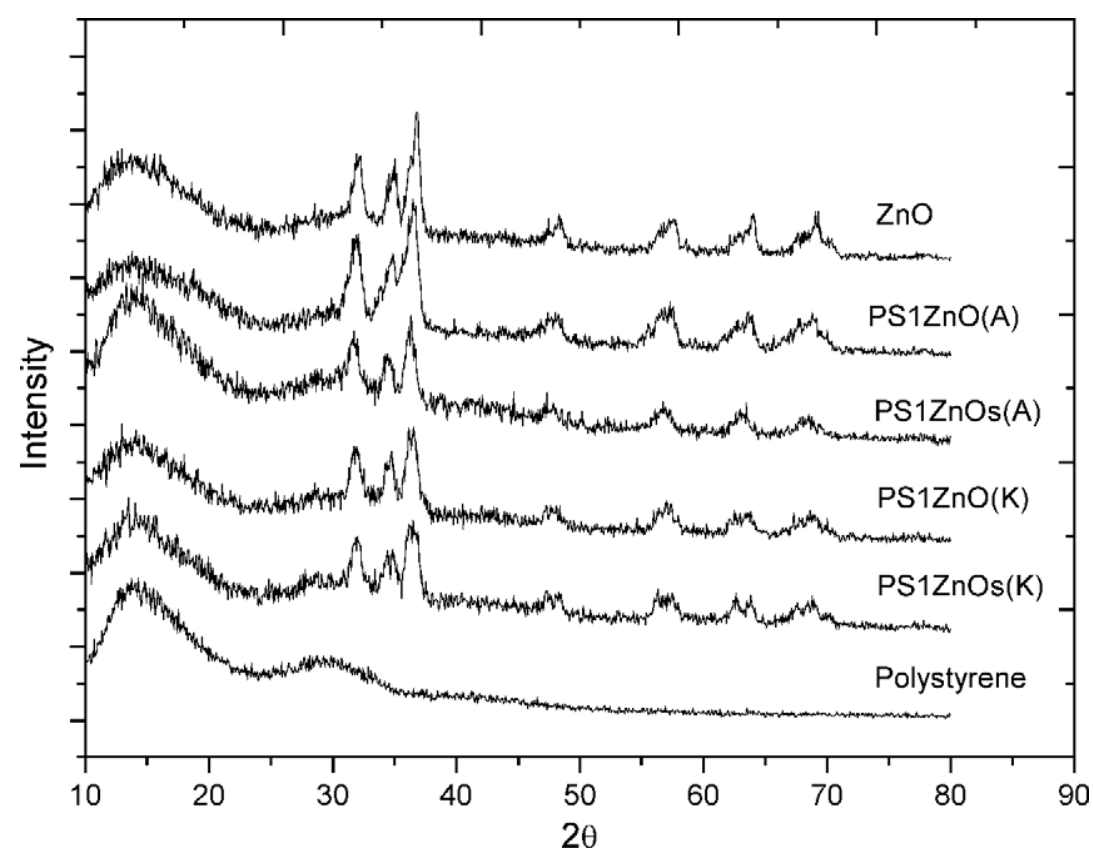

Fig. 2. XRD patterns of $\mathrm{ZnO}, \mathrm{ZnO} /$ polystyrene composites and polystyrene.

\subsection{Characterization}

X-ray diffraction (XRD) patterns were taken to analyze the crystal structures of $\mathrm{ZnO}$, using a MAC Science/MXP X'pert diffractometer with $\mathrm{CuK} \alpha$ radiation at $40 \mathrm{KV}$ and $30 \mathrm{~mA}$. ZnO/polystyrene composite particles were pressed into $\mathrm{KBr}$ pellet and the Fourier transform infrared spectrum (FT-IR) was obtained with BIO-RAD FTS40 in the
$400-4000 \mathrm{~cm}^{-1}$ range with 16 scans. The morphology of $\mathrm{ZnO}$ /polystyrene composite particles was observed with a Hitachi H-7100 transmission electron microscope (TEM).

\section{5. pH adjusting ability}

The $\mathrm{pH}$ adjusting ability of $\mathrm{ZnO} /$ polystyrene composite particles was investigated by dispersing dried $\mathrm{ZnO} /$ poly-

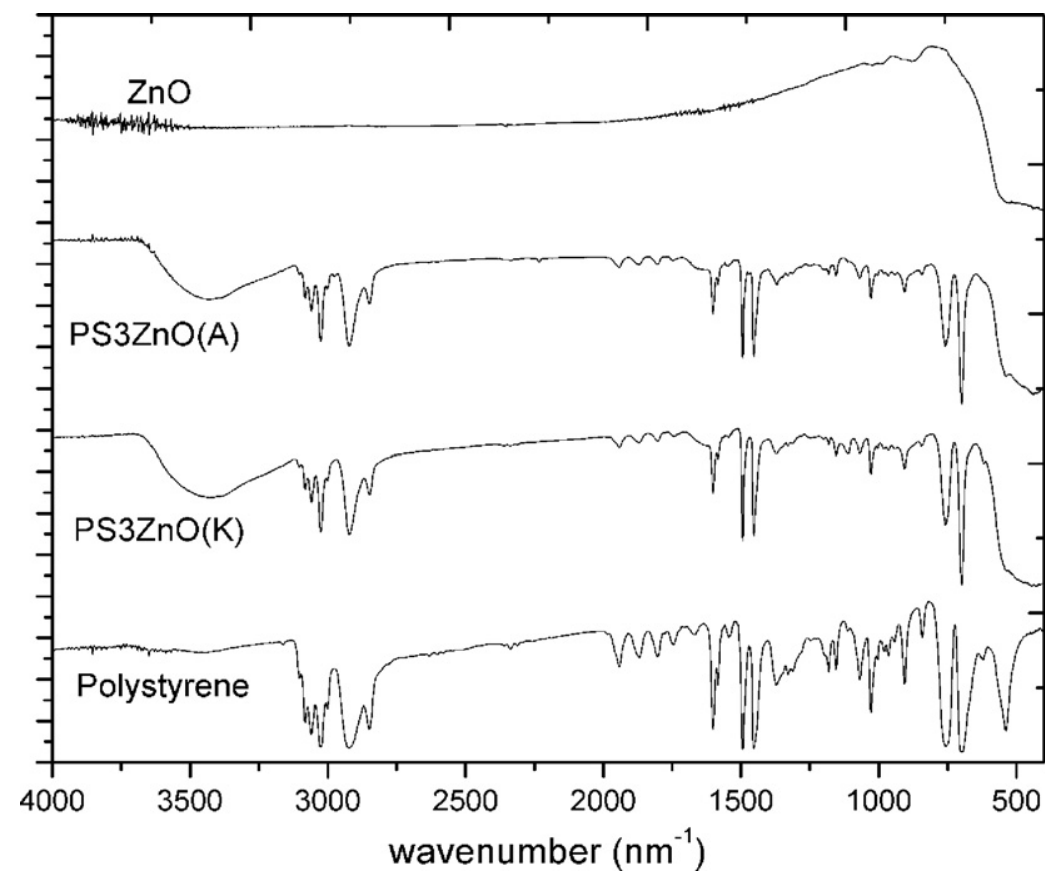

Fig. 3. FT-IR spectra of $\mathrm{ZnO}$, polystyrene, and PS3ZnO composite particles. 

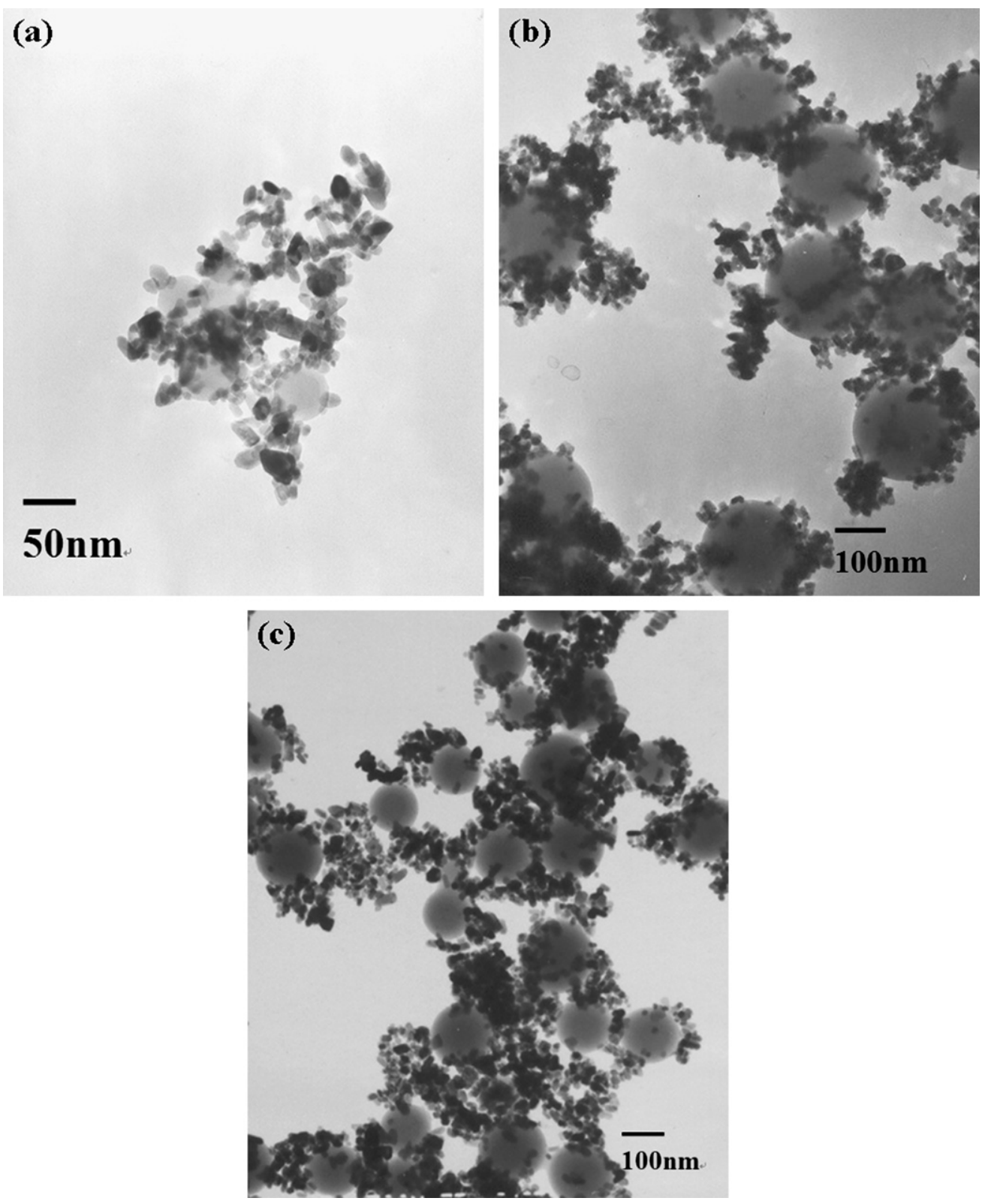

Fig. 4. TEM of (a) PS1ZnO(A), (b) PS3ZnO(A), and (c) PS3ZnOs(A).

styrene composite particles into water solution with different $\mathrm{pH}$ value to form $1000 \mathrm{ppm} \mathrm{ZnO} /$ polystyrene water dispersion. For example, $0.01 \mathrm{~g} \mathrm{PS} 1 \mathrm{ZnO}(\mathrm{A})$ was added to $10 \mathrm{ml}$ of water solutions with $\mathrm{pH} \mathrm{3,5,7}$, and 9 for $10 \mathrm{~min}$. Then the steady-state $\mathrm{pH}$ values before and after $\mathrm{ZnO} /$ polystyrene dispersion were recorded and compared.

\section{Results and discussions}

\subsection{XRD analysis of $\mathrm{ZnO} /$ polystyrene composite particles}

The XRD patterns of $\mathrm{ZnO}, \mathrm{ZnO} /$ polystyrene composites and polystyrene were shown in Fig. 2. Pure $\mathrm{ZnO}$ particles has wurtzite structure and possess main peaks at $2 \theta=$ $32^{\circ}, 34.4^{\circ}, 36.6^{\circ}$, corresponding to (100), (002), and (101) planes, respectively [30]. In this study, ZnO was synthesized from zinc acetate and base. The by-product sodium acetate could be dissolved in water and removed by centrifugation. Therefore sodium acetate was not observed on XRD pattern. The XRD patterns of $\mathrm{ZnO} /$ polystyrene composite particles of different compositions were almost the same as that of $\mathrm{ZnO}$, indicating that the crystal structure of $\mathrm{ZnO}$ was not altered by the presence of polystyrene. In a Pickering emulsion polymerization, $\mathrm{ZnO}$ particles played a role as surfactant, which adsorbed on the surfaces of polystyrene/St particles to form a stable latex. As a result 

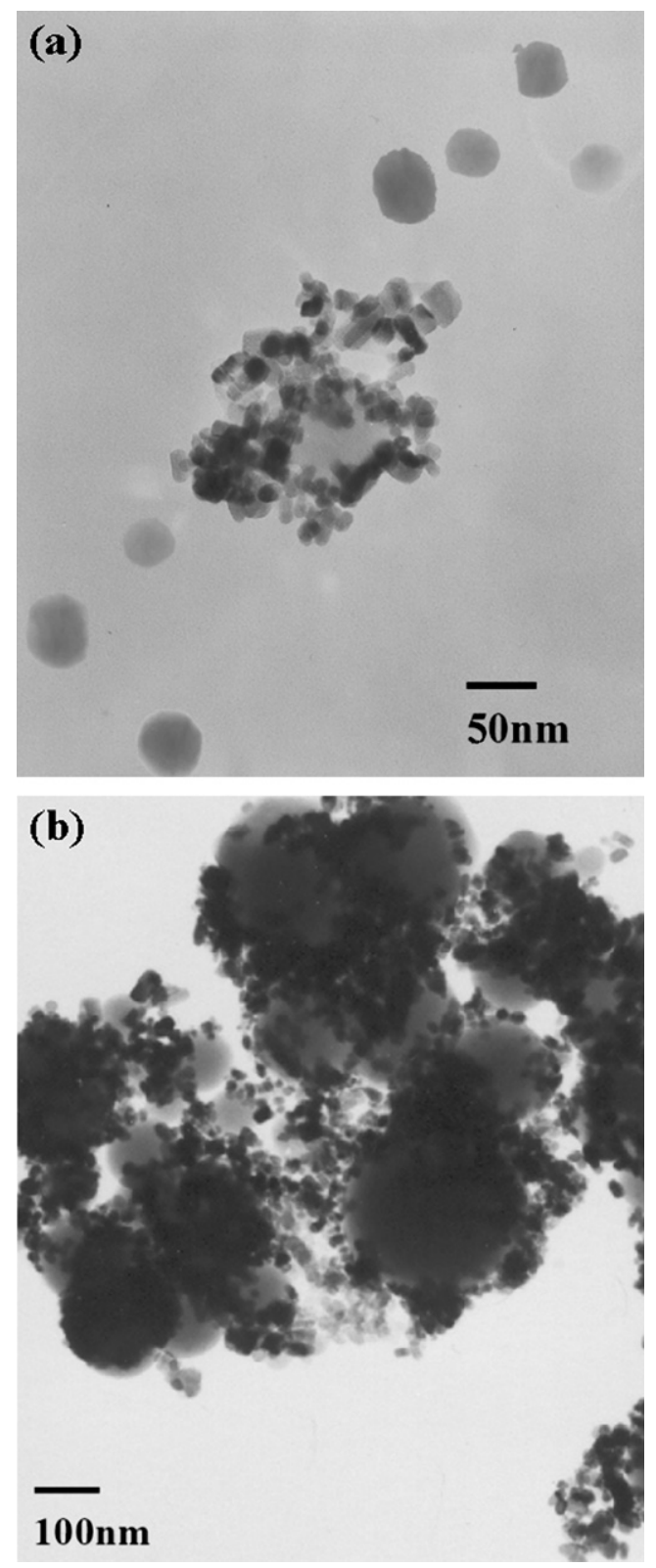

Fig. 5. TEM of (a) $P S 1 Z n O(K)$, (b) $P S 3 Z n O(K)$.

the XRD pattern of $\mathrm{ZnO} /$ polystyrene composite particles exhibited the same characteristics of $\mathrm{ZnO}$.

\subsection{FT-IR analysis of $\mathrm{ZnO} /$ polystyrene composite particles}

Fig. 3 showed the FT-IR spectra of $\mathrm{ZnO}$, polystyrene, and PS3ZnO composite particles. ZnO/polystyrene composite and polystyrene presented the same spectra in the wavenumber range of $700-3100 \mathrm{~cm}^{-1}$ while the weak peak located at $500-700 \mathrm{~cm}^{-1}$ is attributed to the stretching of $\mathrm{Zn}-\mathrm{O}$ bond. Since the characteristic peaks of polystyrene and $\mathrm{ZnO}$ are both presented on PS3ZnO spectrum, it is clear
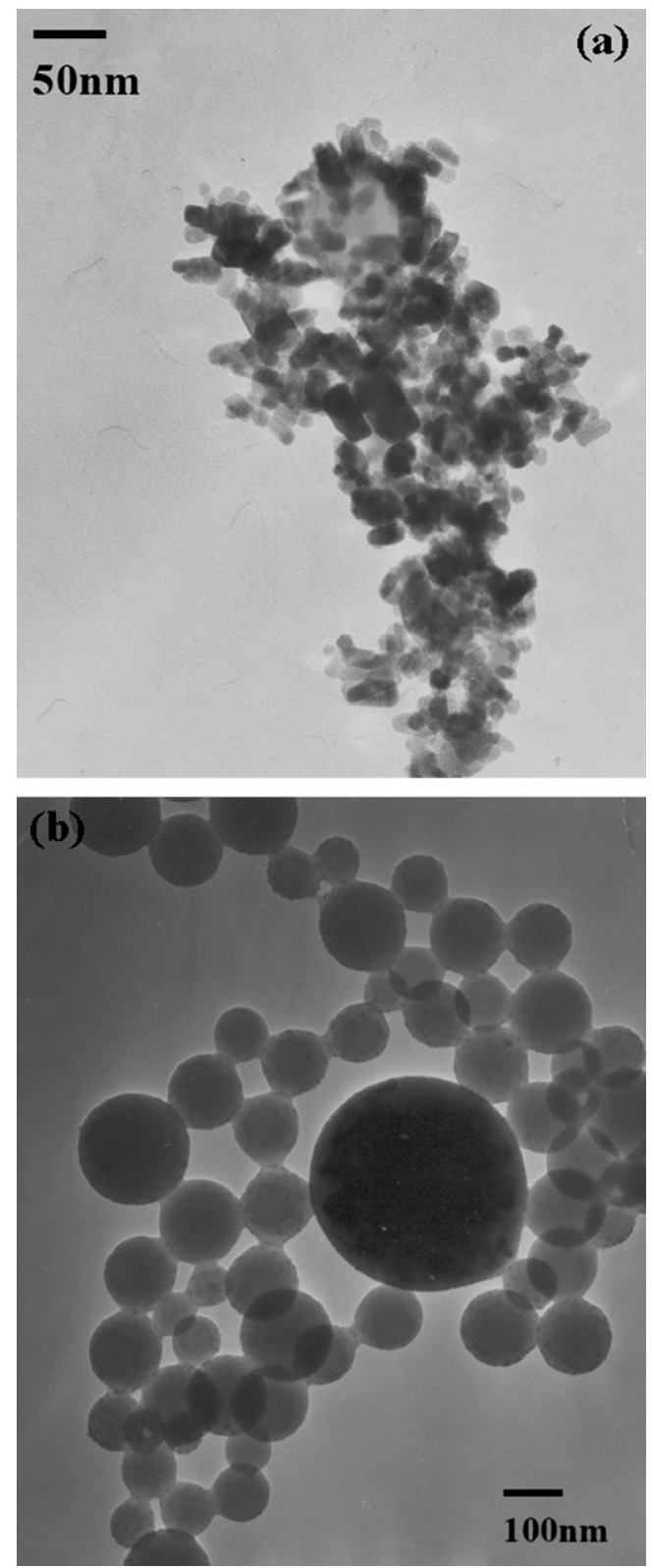

Fig. 6. TEM of (a) PS1ZnOs(K), (b) PS3ZnOs(K).

that $\mathrm{ZnO} /$ polystyrene composite was successfully synthesized in this work.

\subsection{Morphology study of $\mathrm{ZnO} /$ polystyrene composite particles}

The $\mathrm{ZnO} /$ polystyrene composite particles in this study can be classified as polymerization initiated by AIBN and by KPS. During the emulsification process of styrene monomer and $\mathrm{ZnO}$ dispersion, styrene is a hydrophobic monomer and no surfactant was added, phase separation was expected. Nevertheless, this phenomenon was not observed. It indicated that styrene monomer is 


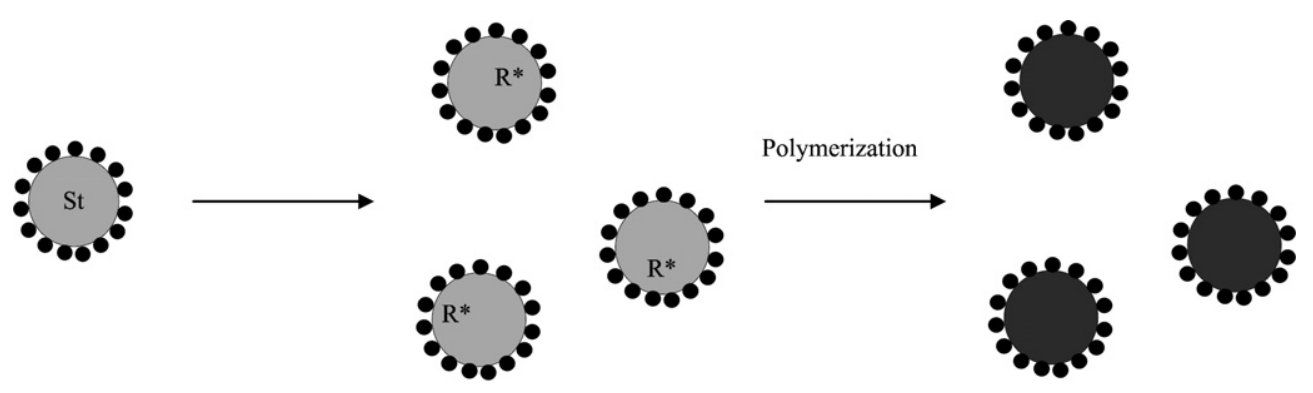

Styrene monomer droplet

$\mathrm{R}^{*} \quad$ Initiators

- $\mathrm{ZnO}$ nanoparticle

Polystyrene latex partilce

Scheme 1. Mechanism of Pickering emulsion polymerization of $\mathrm{ZnO}$ and polystyrene initiated by AIBN.

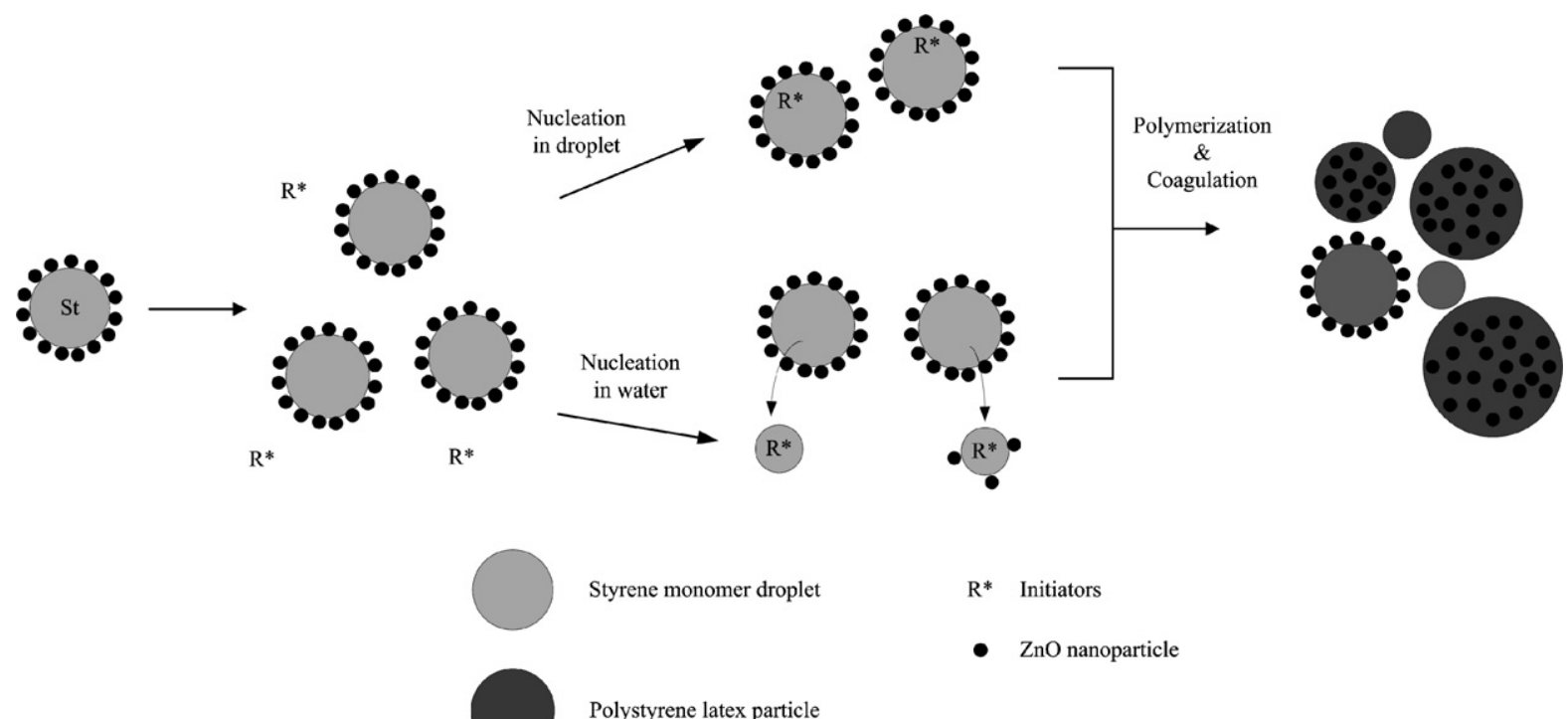

Scheme 2. Mechanism of Pickering emulsion polymerization of $\mathrm{ZnO}$ and polystyrene initiated by KPS.

well-protected by $\mathrm{ZnO}$ nanoparticles to form a stable suspension in water and $\mathrm{ZnO}$ nanoparticles functioned as surfactants.

\subsubsection{AIBN system}

The hydrophobic initiator AIBN was existing in the styrene droplets to initiate polymerization. The nucleation mechanism of polymer particles in such case is mainly droplet nucleation. AIBN molecules would diffuse from water into styrene monomers and initiate the polymerization reaction at $75{ }^{\circ} \mathrm{C}$. The sizes of monomer droplets and polymer latex particles were almost identical. Fig. 4(a) and (b) showed the morphologies of PS1ZnO(A) and PS3ZnO(A). It was seen that the surfaces of polystyrene particles were covered with $\mathrm{ZnO}$ nanoparticles, showing a core-shell structure. As the content of styrene increased from 0.1 to $0.3 \mathrm{~g}$ in the reaction recipes in Table 1 , the size of $\mathrm{ZnO} /$ polystyrene composite particles increased from 50 to $200 \mathrm{~nm}$. When the content of monomer was higher, the relative concentration of $\mathrm{ZnO}$ to styrene decreased. The amount of $\mathrm{ZnO}$ particles was insufficient and it tended to form larger droplets during emulsification, resulting in larger size of $\mathrm{ZnO} /$ polystyrene composite particles. The emulsification methods also affected the particle size. When the content of styrene monomer was 0.1 or $0.2 \mathrm{~g}$, the degree of emulsification by mechanical stirring and that by sonication were comparative. The particle sizes of $\mathrm{PS} 1 \mathrm{ZnO}(\mathrm{A})$ and $\mathrm{PS} 1 \mathrm{ZnOs}(\mathrm{A})$ or PS2ZnO(A) and PS2ZnOs(A) were similar. As the content of styrene monomer increased to $0.3 \mathrm{~g}$, the viscosity 

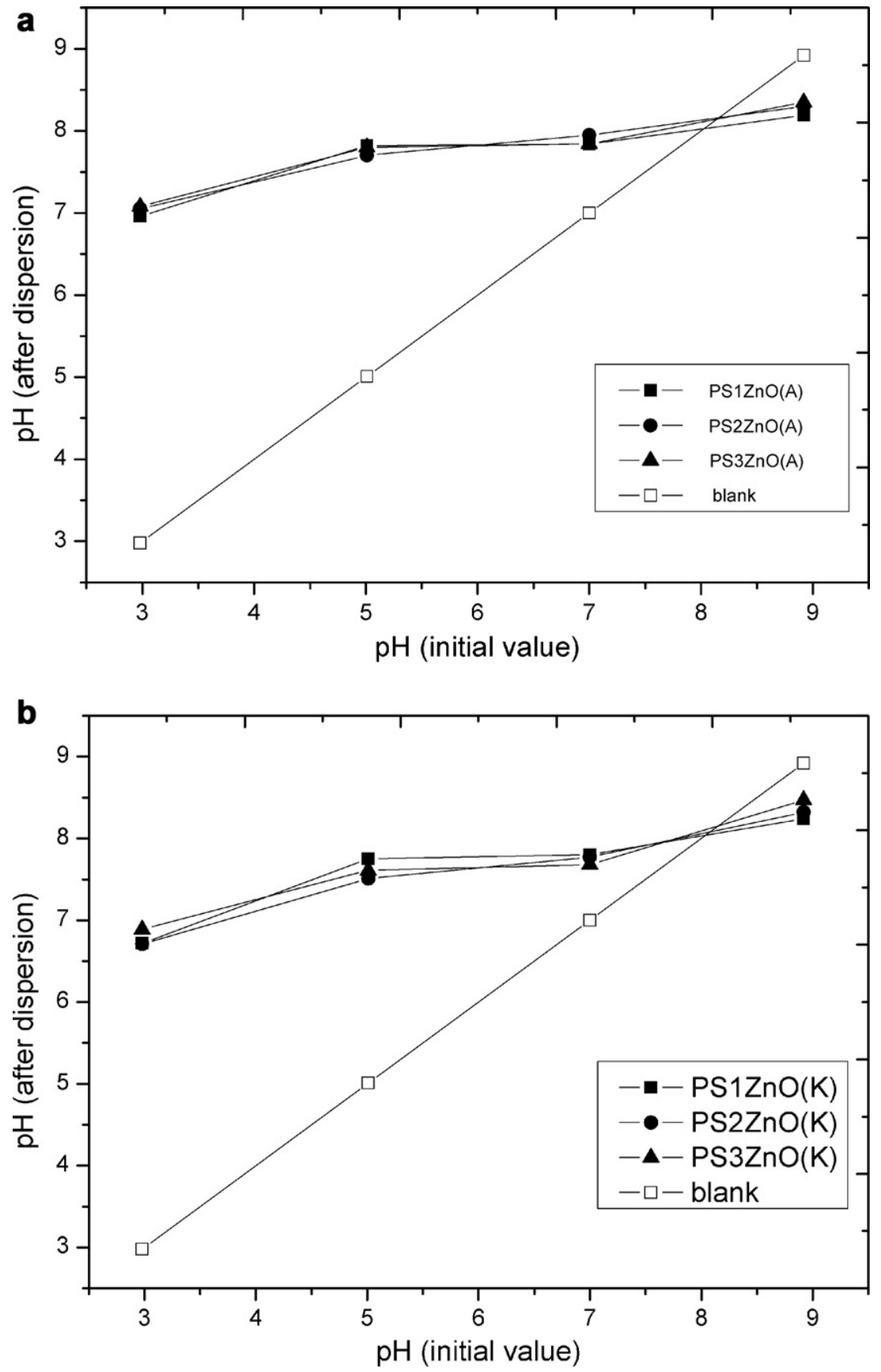

Fig. 7. (a) pH adjusting ability test of ZnO/polystyrene composite particles initiated by AIBN ( $x$ axis: the initial pH value of solution; $y$ axis: the pH value after $\mathrm{ZnO}$ /polystyrene composite particles dispersion; open squares: the blank test). (b) pH adjusting ability test of $\mathrm{ZnO} /$ polystyrene composite particles initiated by $\mathrm{KPS}(x$ axis: the initial $\mathrm{pH}$ value of solution; $y$ axis: the $\mathrm{pH}$ value after $\mathrm{ZnO}$ /polystyrene composite particles dispersion; open squares: the blank test).

of solution started to have an effect on the sized of latex particles. Sonication provide more energy and resulting in smaller latex particle. In Fig. 4(c), the particle size PS3ZnOs(A) is $120 \mathrm{~nm}$, nearly half of that of PS3ZnO(A). Therefore, the size of $\mathrm{ZnO} /$ polystyrene composite particles can be controlled by monomer content (or relative concentration of $\mathrm{ZnO}$ to styrene) and emulsification methods.

\subsubsection{KPS system}

When KPS was used as the initiator, the morphology of composite particles was very different. KPS is a hydrophilic initiator and it alone is capable to stabilize PS particles and form stable latex solution. In the experimental procedure, KPS was added after emulsification of styrene monomer with $\mathrm{ZnO}$. Therefore the stabilization of styrene droplets was attributed to $\mathrm{ZnO}$ particles. The nucleation of polymer 
particles occurred not only in monomer droplets but also in water phase. When the content of styrene was low, as for PS1ZnO(K) shown in Fig. 5(a), large portion of pure PS particles was observed in addition to composite particles with $\mathrm{ZnO}$ nanoparticles on the surface, which indicated that major part of the nucleation of polymer particles occurred in water. As the content of styrene increased to 0.2 and $0.3 \mathrm{~g}$ for $\mathrm{PS} 2 \mathrm{ZnO}(\mathrm{K})$ and $\mathrm{PS} 3 \mathrm{ZnO}(\mathrm{K})$, respectively, the number of styrene droplets increased. Therefore more radicals from KPS would be captured by styrene droplets and the probability of nucleation in droplets would be raised. On the other hand, the ratio of $\mathrm{ZnO}$ to styrene decreased as a consequence of styrene increasing. The $\mathrm{ZnO} /$ polystyrene composite latex became less stable for the lack of $\mathrm{ZnO}$ nanoparticles as stabilizer. As a result, coagulation occurred because of the interaction between $\mathrm{ZnO}$ and the PS latex particles. Morphologically, ZnO would be embedded inside the large coagulation of PS particles as shown in Fig. 5(b) for PS3ZnO(K). In sum, three kinds of particles were observed: PS with $\mathrm{ZnO}$ nanoparticles on the surfaces due to nucleation in droplets, pure PS particles due to nucleation in water, and $\mathrm{ZnO}$-embedded PS particles due to coagulation of particles.

Looking into the morphologies of latex particles emulsified by sonication instead of mechanical stirring, since the number of styrene droplets increased after sonication, the probability of droplet nucleation would be enhanced, as shown in Fig. 6(a) for PS1ZnOs(K). However, when styrene monomer was increased to 0.2 or $0.3 \mathrm{~g}$ for $\operatorname{PS} 2 \mathrm{ZnOs}(\mathrm{K})$ and $\mathrm{PS} 3 \mathrm{ZnOs}(\mathrm{K})$, respectively, the relatively insufficient $\mathrm{ZnO}$ nanoparticles resulted in less stable droplets, thus both nucleation in water and coagulation of particles increased. It can be seen from Fig. 6(b) for PS3ZnOs(K) that pure PS particles nucleated in water and coagulation thus formed large composite particles were together existing in the reaction systems.

From the discussion above, the mechanism of Pickering emulsion polymerization of $\mathrm{ZnO}$ and polystyrene can be summarized as Schemes 1 and 2. For AIBN system, styrene monomer was well-protected by $\mathrm{ZnO}$ nanoparticles and polymerization reaction occurred mainly in styrene droplets, since AIBN was a hydrophobic initiator. The resulting composite particles showed core-shell morphology. The difference in morphology of particles between mechanical stirring and sonication on emulsification was only apparent when the content of styrene was high. For KPS system, the proportion of polymer particle nucleation in droplets decreased but nucleation in water increased due to the hydrophilic property of KPS. Both pure PS particles and $\mathrm{ZnO} / \mathrm{PS}$ composite particles were observed. Besides, coagulation of particles resulted in $\mathrm{ZnO}$-embedded morphology.

\section{4. $\mathrm{pH}$ adjusting ability investigation}

$\mathrm{ZnO}$ is an amphoteric substance that can react with either an acid or a base. In a acid medium, $\mathrm{ZnO}$ reacts with proton to form $\mathrm{Zn}^{2+}$ and $\mathrm{H}_{2} \mathrm{O}$, while in a base medium, $\mathrm{ZnO}$ reacts with hydroxide group to form $\left[\mathrm{Zn}(\mathrm{OH})_{4}\right]^{2-}$. This property makes $\mathrm{ZnO}$ a good material for $\mathrm{pH}$ adjusting. In this study, the variation of $\mathrm{pH}$ value of $1000 \mathrm{ppm}$ of $\mathrm{ZnO} /$ polystyrene water dispersion with different $\mathrm{pH}$ was com- pared. As shown in Fig. 7, both $\mathrm{ZnO} /$ polystyrene composite particles initiated by AIBN and KPS adjusted water solution from $\mathrm{pH} 3,5,7$, or 9 to $7-8$. That is, $\mathrm{ZnO} /$ polystyrene composite particles as-prepared could adjust acid and base solution to neutral. They are potential to be good $\mathrm{pH}$ adjusting materials. To increase the range of $\mathrm{pH}$ adjusting and their application are under study.

\section{Conclusion}

By Pickering emulsion polymerization, $\mathrm{ZnO} /$ polystyrene composite particles were successfully synthesized. ZnO nanoparticles acted as surfactant in the polymerization of styrene. The crystal structure of $\mathrm{ZnO}$ in $\mathrm{ZnO} /$ polystyrene composite particles was not altered. Using different initiators in the polymerization, it resulted in different morphologies of $\mathrm{ZnO} /$ polystyrene composite particle. Due to the difference of degree of hydrophilicity, AIBN-initiated system resulted in $\mathrm{ZnO}$-shell and PS-core composite particles while KPS-initiated system resulted in pure PS particles and composite particles with $\mathrm{ZnO}$ on the surface or $\mathrm{ZnO}$ embedded inside. $\mathrm{ZnO} /$ polystyrene composite particles showed good $\mathrm{pH}$ adjusting ability and they are potential as a $\mathrm{pH}$ buffering material.

\section{Acknowledgement}

The authors are grateful to the financial support from Ministry of Economic Affairs "Technology Development Program for Academia" under contract 95-EC-17-A-08S1-015.

\section{References}

[1] Yi G-C, Wang C, Park WI. ZnO nanorods: synthesis, characterization and applications. Semicond Sci Tech 2005;20(4):S22-34.

[2] Beek WJE, Wienk MM, Janssen RAJ. Hybrid polymer solar cells based on zinc oxide. J Mater Chem 2005;15:2985-8.

[3] Sahay PP. Zinc oxide thin film gas sensor for detection of acetone. J Mater Sci 2005;40:4383.

[4] Jiaqiang X, Yuping C, Daoyong C, Jianian S. Hydrothermal synthesis and gas sensing characters of $\mathrm{ZnO}$. Sensor Actuat $\mathrm{B}$ Chem 2006;113(1):526-31.

[5] Kong L, Li F, Zhang L, Yao X. Sol-gel glass-coated zinc oxide for varistor applications. J Mater Sci Lett 1998;17(9):769-71.

[6] Hao XT, Zhu FR, ONg KS, Tan LW. Hydrogenated aluminium-doped zinc oxide semiconductor thin films for polymeric light-emitting diodes. Semicond Sci Tech 2006;21(1):48-54.

[7] Shih W-C, Wu M-S. Growth of ZnO films on GaAs substrates with a SiO2 buffer layer by RF planar magnetron sputtering for surface acoustic wave applications. J Cryst Growth 1994;137(3-4):319-25.

[8] Radovanovic RV, Norberg NS, McNally KE, Gamelin DR. Colloidal transition-metal-doped $\mathrm{ZnO}$ quantum dots. J Am Chem Soc 2002;129(51):15192-3.

[9] Khrenov V, Klapper M, Koch M, Mullen K. Surface functionalized ZnO particles designed for the use in transparent nanocomposites. Macromol Chem Phys 2005;206(1):95-101.

[10] Toutorski IA, Tkachenko TE, Pokidko BV. Mechanical properties and structure of zinc-containing latex-silicate composites. J Sol-Gel Sci Tech 2003;26(1-3):505-9.

[11] Taubert A, Palms D, Weiss Ö, Piccini M-T, Batchelder DN. Polymerassisted control of particle morphology and particle size of zinc oxide precipitated from aqueous solution. Chem Mater 2002;14(6):2594-601.

[12] Purica M, Budianu E, Rusu E, Danila M, Gavrila R. Optical and structural investigation of $\mathrm{ZnO}$ thin films prepared by chemical vapor deposition (CVD). Thin Solid Films 2002;403-404:485-8.

[13] Audebrand N, Auffrédic J-P, Louër D. X-ray diffraction study of the early stages of the growth of nanoscale zinc oxide crystallites 
obtained from thermal decomposition of four precursors. General concepts on precursor-dependent microstructural properties. Chem Mater 1998;10(9):2450-61.

[14] Yang Y, Chen H, Zhao B, Bao X. Size control of ZnO nanoparticles via thermal decomposition of zinc acetate coated on organic additives. J Cryst Growth 2004;263(1-4):447-53.

[15] Lu C-H, Yeh C-H. Influence of hydrothermal conditions on the morphology and particle size of zinc oxide powder. Ceram Int 2000;26(4):351-7.

[16] Trindade T, Jesus JDP, O’Brien P. Preparation of zinc oxide and zinc sulfide powders by controlled precipitation from aqueous solution. J Mater Chem 1994;4(10):1615-7.

[17] Al-Hilli SM, Al-Mofarji RT, Willandera M. Zinc oxide nanorod for intracellular pH sensing. Appl Phys Lett 2006;89:173119.

[18] Pickering SU. J Chem Soc 1907;91:2001-21.

[19] He Y. Preparation of polyaniline/nano-ZnO composites via a novel Pickering emulsion route. Powder Technol 2004;147(1-3):59-63.

[20] He Y. A novel emulsion route to sub-micrometer polyaniline/nanoZnO composite fibers. Appl Surf Sci 2005;249(1-4):1-6.

[21] He Y, Li K. Novel Janus $\mathrm{Cu} 2(\mathrm{OH}) 2 \mathrm{CO} / \mathrm{CuS}$ microspheres prepared via a Pickering emulsion route. J Colloid Interf Sci 2007;306(2):296-9.

[22] Binks BP, Lumsdon SO. Influence of particle wettability on the type and stability of surfactant-free emulsions. Langmuir 2000;16(23): 8622-31.
[23] Binks BP, Clint JH. Solid wettability from surface energy components: relevance to Pickering emulsion. Langmuir 2002;18(4):1270-3.

[24] Sacanna S, Philipse AP. A generic signle-step synthesis of monodisperse core/shell colloids based on spontaneous Pickering emulsification. Adv Mater 2007;19(22):3824-6.

[25] Hasell T, Yang J, Wang W, Li J, Brown PD, Poliakoff M, et al. Preparation of polymer-nanopartilce composite beads by a nanoparticle-stabilised suspension polymerisation. J Mater Chem 2007; 17(41):4382-6.

[26] He Y. Synthesis of polyaniline/nano-CeO2 composite microspheres via a solid-stabilized emulsion route. Mater Chem Phys 2005;92(1):134-7.

[27] Liu Y, Chen X, Wang R, Xin JH. Polymer microspheres stabilized by titania nanoparticles. Mater Lett 2006;60(29-30):3731-4.

[28] Binks BP, Philip J, Rodrigues JA. Inversion of silica-stabilized emulsions induced by particle concentration. Langmuir 2005;21(8):3296-302.

[29] Binks BP, Whitby CP. Nanoparticle silica-stabilised oil-in-water emulsions: improving emulsion stability. Colloids Surf A Physicochem Eng Aspects 2005;253(1-3):105-15.

[30] He Y, Sang W, Wang J, Wu R, Min J. Polymer-assisted complexing controlled orientation growth of $\mathrm{ZnO}$ nanorods. J Nanoparticle Res 2005;7:307-10. 